\title{
A novel de novo truncating TRIM8 variant associated with childhood-onset focal segmental glomerulosclerosis without epileptic encephalopathy: a case report
}

Yoko Shirai ${ }^{1}$, Kenichiro Miura', Naoto Kaneko ${ }^{1}$, Kiyonobu Ishizuka' ${ }^{1}$, Amane Endo², Taeko Hashimoto ${ }^{3}$, Shoichiro Kanda ${ }^{4}$, Yutaka Harita ${ }^{4}$ and Motoshi Hattori ${ }^{{ }^{*}}$ (i)

\begin{abstract}
Background: Heterozygous truncating variants in the Tripartite motif containing 8 (TRIM8) gene have been reported to cause epileptic encephalopathy, both with and without proteinuria. A recent study showed a lack of TRIM8 protein expression, with suppressor of cytokine signaling 1 (SOCS1) overexpression, in podocytes and tubules from a patient with a TRIM8 variant, who presented with epileptic encephalopathy and focal segmental glomerulosclerosis (FSGS). To date, no patients with TRIM8 variants who presented with nephrotic syndrome but without neurological manifestations have been described.
\end{abstract}

Case presentation: An 8-year-old girl presented with nephrotic syndrome, without epilepsy or developmental delay. Her kidney biopsy specimens showed FSGS and cystic dilatations of the distal tubules. Whole-exome sequencing identified a novel de novo heterozygous variant in the C-terminal encoding portion of TRIM8 (c.1461C>A), resulting in a premature stop codon (p.Tyr487*). Reverse transcription-polymerase chain reaction using peripheral blood mononuclear cells identified the mRNA sequence of the mutant allele, which confirmed an escape from nonsensemediated mRNA decay. Immunofluorescence studies showed a lack of TRIM8 expression in glomerular and tubular cells and cystic dilatation of distal tubules. Immunohistochemical studies showed overexpression of SOCS1 in glomerular and tubular cells.

Conclusions: We reported a patient with FSGS, associated with a de novo heterozygous TRIM8 variant, without any neurological manifestations. Our results expanded the clinical phenotypic spectrum of TRIM8 variants.

Keywords: Focal segmental glomerulosclerosis, Nonsense-mediated mRNA decay, Suppressor of cytokine signaling 1, Tripartite motif containing 8, Case report

\section{Background}

Focal segmental glomerulosclerosis (FSGS) describes a histologic lesion that causes podocyte injury. To date, More than 50 causative genes have been associated with

\footnotetext{
*Correspondence: hattori@twmu.ac.jp

${ }^{1}$ Department of Pediatric Nephrology, Tokyo Women's Medical University, Tokyo, Japan

Full list of author information is available at the end of the article
}

genetic forms of FSGS [1, 2]

Sakai et al. described a 10-year-old boy with epileptic encephalopathy, severe developmental delay, and a de novo variant the tripartite motif containing 8 (TRIM8) gene [3]. Assoum et al. described five additional individuals of childhood-onset epileptic encephalopathy associated with heterozygous de novo variants in the C-terminus-encoding portion of TRIM8, including three 
individuals who presented with proteinuria [4]. Recently, Warren et al. reported an individual with epileptic encephalopathy and nephrotic syndrome with a TRIM8 variant, and his kidney specimen showed FSGS [5]. They also performed immunohistochemical (IHC) staining, using an anti-TRIM8 antibody, and demonstrated a lack of TRIM8 protein expression, with suppressor of cytokine signaling 1 (SOCS1) overexpression, which is regulated by TRIM8, in the podocytes and tubules [5]. In addition, McClatchey et al. presented an individual with FSGS which required renal replacement therapies, but only mild neurodevelopmental problems [6].

Here, we report a patient with a novel, de novo, heterozygous nonsense variant in the last exon of TRIM8, who presented with nephrotic range proteinuria and progressed to end-stage renal disease (ESRD) but did not present with any neurological manifestations. A kidney biopsy showed FSGS and cystic dilatations of the tubules. To evaluate pathogenicity of the patient's nonsense TRIM8 variant and characterize the pathological changes in glomerular and tubulointerstitial lesions, we performed mRNA analysis in mononuclear cells and immunofluorescence studies on kidney specimens from the present patient and control samples. In addition, the loci of TRIM8 nonsense variants and clinical manifestations in previously reported individuals and the present patient were reviewed.

\section{Case presentation}

A girl presented with asymptomatic proteinuria, which was revealed by a urinary screening test performed in Japan when she was 3 years old. She had no family history of renal or neurological disorders. The urine protein to creatinine ratio (UPCR) was $1.0-1.5 \mathrm{~g} / \mathrm{gCr}$ (reference range $<0.2 \mathrm{~g} / \mathrm{gCr})$ at that time. Ultrasonography revealed normal echogenicity in both kidneys. She developed nephrotic syndrome, without systemic edema, at the age of 8 years. Polyuria and polydipsia with a urine output of $3 \mathrm{~L}$ in a day were also documented. UPCR was $11.5 \mathrm{~g} / \mathrm{gCr}$, and the serum albumin level was $2.1 \mathrm{~g} / \mathrm{dL}$ (reference range 3.7-5.5 g/dL). The serum creatinine level was $0.97 \mathrm{mg} / \mathrm{dL}$ (eGFR was $46.8 \mathrm{~mL} / \mathrm{min} / 1.73 \mathrm{~m}^{2}$ ). The urine specific gravity was 1.008 , and urinary beta 2-microglobulin increased to $9,269 \mu \mathrm{g} / \mathrm{L}$ (reference range $\leq 150 \mu \mathrm{g} / \mathrm{L}$ ). A kidney biopsy revealed that 13 (52\%) of 25 glomeruli showed segmental or global sclerosis. Furthermore, two glomeruli showed cellular lesions, which were characterized by swollen, vacuolated, and proliferative glomerular epithelial cells, throughout Bowman's space. The underlying glomerular capillaries were partially collapsed and occluded by swollen endothelial cells and karyorrhexis, which was consistent with a pathological diagnosis of FSGS (Fig. 1A) [7]. No glomeruli with collapse and overlying podocyte hypertrophy and hyperplasia were not observed. Cystic dilatations of the tubules and interstitial fibrosis were also observed (Fig. 1B). The patient presented with no neurological manifestations, such as seizures or developmental delays. Brain magnetic resonance imaging (MRI) and electroencephalogram detected no abnormalities. She could hold her head up at 4 months old, sit at 8 months old, pull up to stand at 9 moths and speak single words at 1 year and 6 months old. She did not need special support to attend school. Her renal function continued to deteriorate, and she eventually developed ESRD, despite the administration of angiotensin receptor blockers. At 9 years of age, pre-emptive kidney transplantation was performed, with a kidney donated by her mother. No recurrence of proteinuria has been observed for 1 year and 9 months after transplantation.
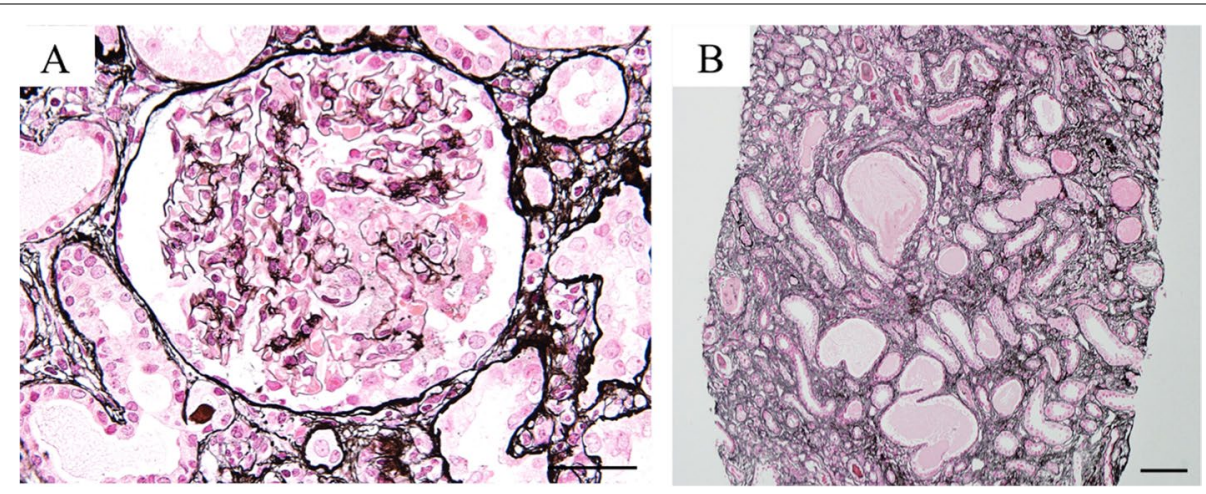

Fig. 1 Pathological findings of the kidney specimen obtained from the present patient. (A) The glomeruli in kidney specimens obtained from the present patient showed cellular lesions, characterized by swollen, vacuolated, and proliferative glomerular epithelial cells throughout Bowman's space. The underlying glomerular capillaries were partially collapsed and occluded by swollen endothelial cells and karyorrhexis (original magnification $\times 400$. Scale bar $=50 \mu \mathrm{m}$ ); (B) Cystic dilatations of the tubules were also observed (original magnification $\times 200$. Scale bar $=50 \mu \mathrm{m}$ ) 
We performed whole-exome analysis using a previously described method [8], focusing on variants in the genes that are currently known to cause FSGS or nephronophthisis (Tables S1 and S2), and identified a de novo novel heterozygous $\mathrm{C}$ to A transition (c.1461C > A) in the last exon of TRIM8, resulting in a premature stop codon (p.Tyr487*). The alternative and reference allele counts were 68 (46\%) and 80 (54\%), respectively. Sanger sequencing showed that the individual had the variant but that her parents did not. This variant was absent in population databases including the Exome Aggregation Consortium database (ExAC, http://exac.broadinstitute. org/), Genome Aggregation Database (gnomAD, http:// gnomad.broadinstitute.org), 1000 Genomes (1000G, http://asia.ensembl.org/Homo_sapiens/Info/Index), ESP6500 (http://evs.gs.washington.edu/EVS/). No additional pathogenic variants in the genes that are currently known to cause FSGS or nephronophthisis were identified (Tables S1 and S2). This variant was classified as pathogenic (PVS1, PM1, PM2, PM6, and PP4) based on the criteria developed by the American College of Medical Genetics and Genomics [9].

The sequence analysis of mRNA was performed as previouly reported methods [10]. RNA was extracted from peripheral blood mononuclear cells with the RNeasy Mini Kit (QIAGEN), according to the manufacturer's instructions. The RNA was treated with DNase (QIAGEN) to avoid genomic DNA contamination, and $200 \mathrm{ng}$ of total RNA was reverse transcribed, using the SuperScript VILO cDNA Synthesis Kit (Thermo Fisher Scientific) for the mRNA analysis. The following primers were used to amplify and sequence exon 6 of TRIM8 from cDNA: 5'-GAGTGTCCCCCT GTACCCTT -3' (forward) and 5'-CTACAGGGTGTA TGGGCAGC-3' (reverse). Polymerase chain reaction experiments were performed, using Invitrogen Platinum II Taq Hot-Start DNA Polymerase (Thermo Fisher Scientific) and T100TM Thermal Cycler (BioRad Laboratories) identifing mRNA sequences transcribed from the TRIM8 mutant allele (Fig. 2), which confirmed the escape from nonsense-mediated mRNA decay (NMD) [11].

Immunohistochemical analysis were performed using the formalin-fixed paraffin-embedded kidney biopsy specimens obtained from the present patient and nine control individuals consisting of three living kidney transplantation donors who served as normal controls, five patients with primary FSGS and one patient with nephronophthisis who served as disease controls. We performed autoclave-based antigen retrieval, for 15 min at $105{ }^{\circ} \mathrm{C}$, in Bond Epitope Retrieval Solution 2 (Leica Biosystems Newcastle, Ltd., Newcastle Upon Tyne, UK). Specimens were incubated with goat polyclonal antibody against an epitope corresponding to amino acids 540-551, at the C-terminus of human TRIM8 (Abcam, Cambridge, MA, USA; catalog no. ab4302), overnight, at a dilution of 1:500 [5]. Immunofluorescence staining, using the anti-TRIM8 antibody in normal control specimens, is shown in Fig. 3 (Fig. 3A-E). TRIM8 expression was observed in the nuclei of all glomerular cells (Fig. 3A-C). Double immunostaining with mouse anti-human podocalyxin monoclonal antibody (PHM5, Merck Millipore, Darmstadt, Germany), at a dilution of 1:100 which was used

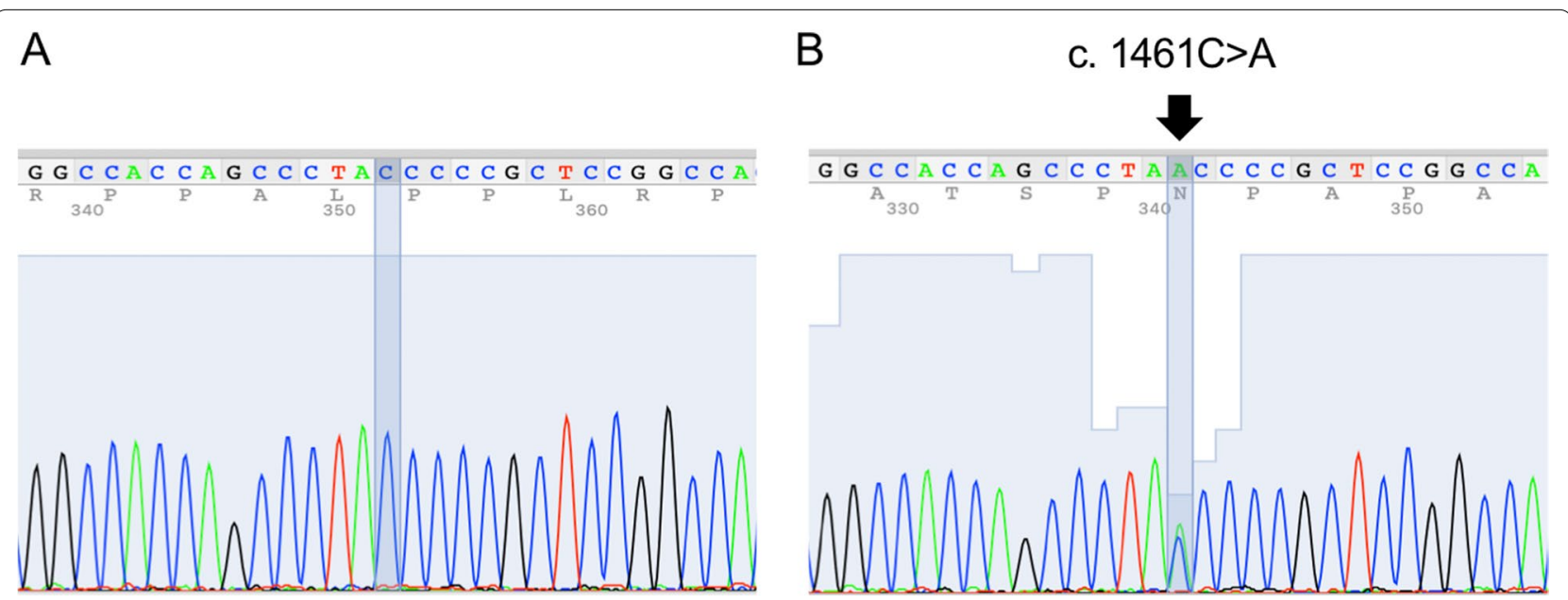

Fig. 2 Sequence analysis of mRNA showed mutant allele of the TRIM8 gene. The TRIM8 exon 6 sequences from a control sample (A) and the present patient (B) are shown. The arrow in panel (B) indicates the base substitution, in a heterozygous state. The polymerase chain reaction product was not amplified when RNA samples were treated without reverse transcriptase, which confirmed the lack of genomic DNA contamination 

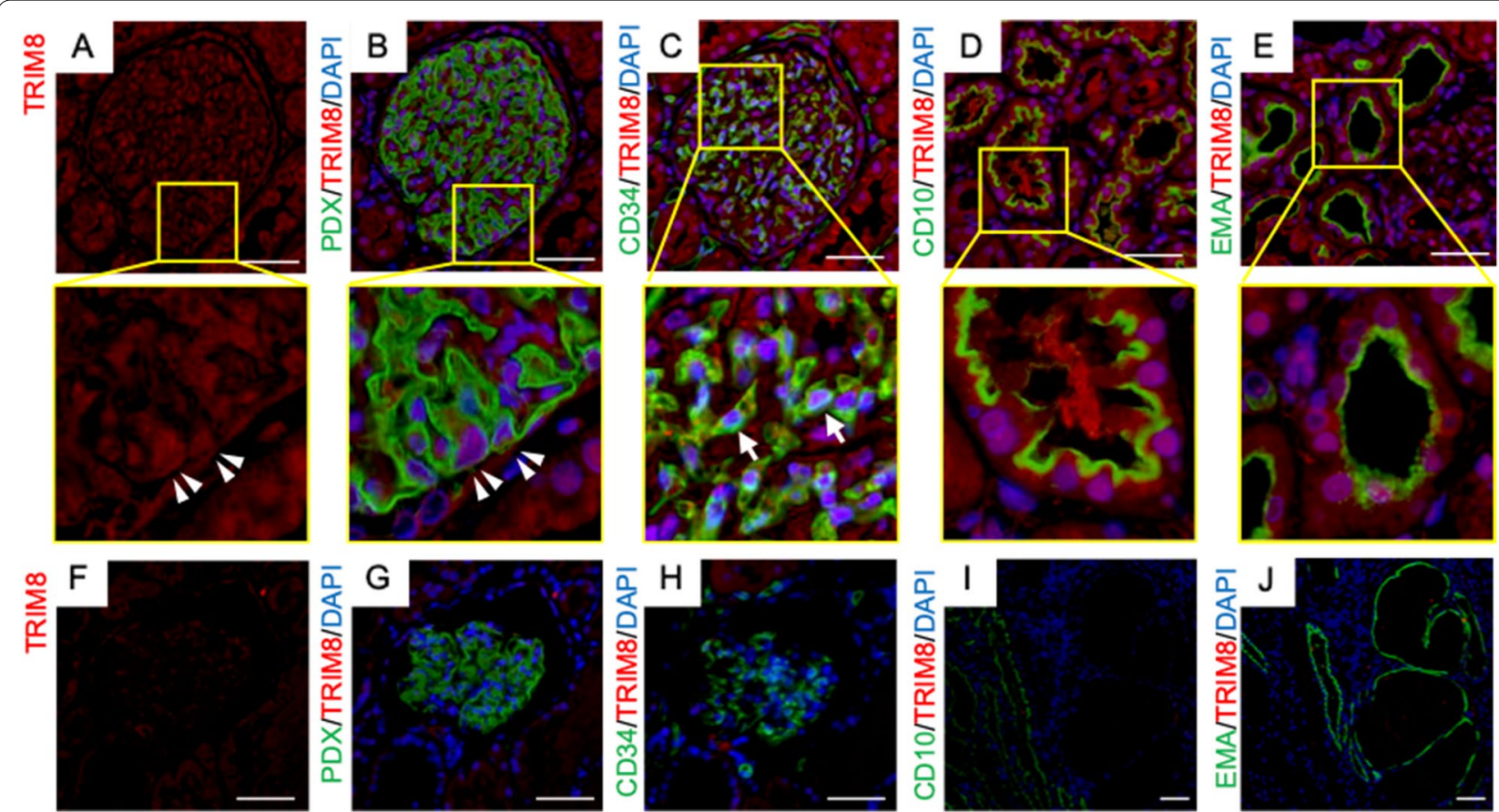

Fig. 3 Immunofluorescence staining using anti-TRIM8 antibody. Immunofluorescence staining of the kidney specimen, using an anti-TRIM8 antibody; (A) normal control, (F) the present patient, combined with anti-podocalyxin antibody, (B) normal control, (G) the present patient; anti-CD34 antibody, (C) normal control, (H) the present case; anti-CD10 antibody (D) normal control, (I) the present patient; and anti-EMA antibody (E) normal control, (J) the present patient (original magnification $\times 400$. Scale bar $=50 \mu \mathrm{m}$ ). TRIM8 was expressed in the nuclei of podocytes (podocalyxin-positive cells, B) (arrowheads) and endothelial cells (CD34-positive cells, C) (arrows). Proximal and distal tubular epithelial cells also showed the nuclear expression of TRIM8 protein in the normal control specimen ( $\mathbf{D}$ and $\mathbf{E}$ ). TRIM8 expression was not observed in any cells in the kidney tissue obtained from the present patient $(\mathbf{F}-\mathbf{J})$. Tubules with cystic dilatation were positive for EMA but negative for CD10 (I and $\mathbf{J})$.CD10, Cluster of differentiation 10; CD34, Cluster of differentiation 34; EMA, epithelial membrane antigen; TRIM8, tripartite motif containing 8

as a podocyte marker (Fig. 3B) [12] and mouse antihuman cluster of differentiation 34 (CD34) monoclonal antibody (QBEND/10, Leica Microsystems, Wetzlar, Germany), at a dilution of 1:40 which was used as an endothelial cell marker (Fig. 3C) [13] showed that TRIM8 was expressed in the nuclei of podocytes and endothelial cells, respectively. Proximal tubular cells that were identified by mouse anti-human cluster of differentiation 10 (CD10) monoclonal antibody (56C6, Leica Microsystems, Wetzlar, Germany) without dilution [14] and distal tubular cells that were identified by mouse anti-human epithelial membrane antigen (EMA) monoclonal antibody (Clone E29, Dako, Santa Clara, California, USA) without dilution [15] also showed the nuclear expression of TRIM8 protein (Fig. 3D and E). Similar findings were observed in specimens from disease controls (Fig. S1). In contrast, the present patient showed a lack of TRIM8 protein expression in any cells in the glomeruli and tubules (Fig. 3F-J). The tubules showing cystic dilatation were positive for EMA, but negative for CD10, indicating that cystic dilatation was evident in the distal tubules (Fig. 3I and J). IHC staining, using anti-SOCS1 goat polyclonal antibody (Abcam, catalog no. ab9870), at a dilution of 1:500 [5] of the kidney biopsy specimens derived from the present patient showed stronger cytoplasmic SOCS1 expression in glomerular and tubular cells than observed in control samples (Fig. S2).

\section{Discussion and conclusions}

We reported the first patient with a de novo variant in TRIM8 who developed nephrotic syndrome and ESRD without any neurological manifestations. Immunofluorescence examination indicated that the variant identified in the present case (p.Tyr487*) is pathogenic because TRIM8 expression was decreased in all kidney cells, consistent with a previous report [5]. Additionally, sequence analysis of mRNA of samples from the present patient confirmed the escape of the mutant allele from NMD. These findings suggested a dominant-negative effect for the heterozygous nonsense variant, which could affect the E3 ubiquitin ligase activity of TRIM8 in the kidney $[5,16]$. 


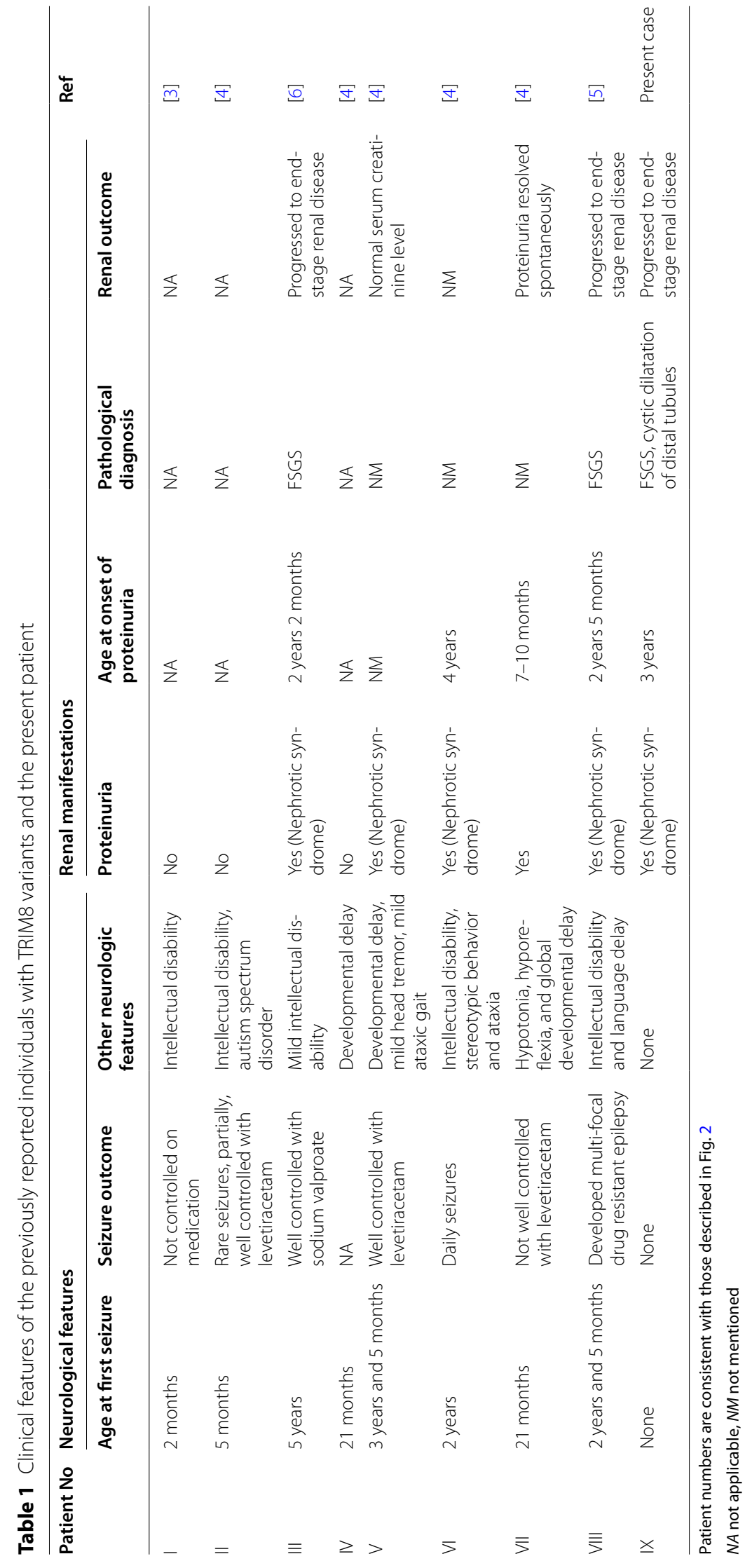




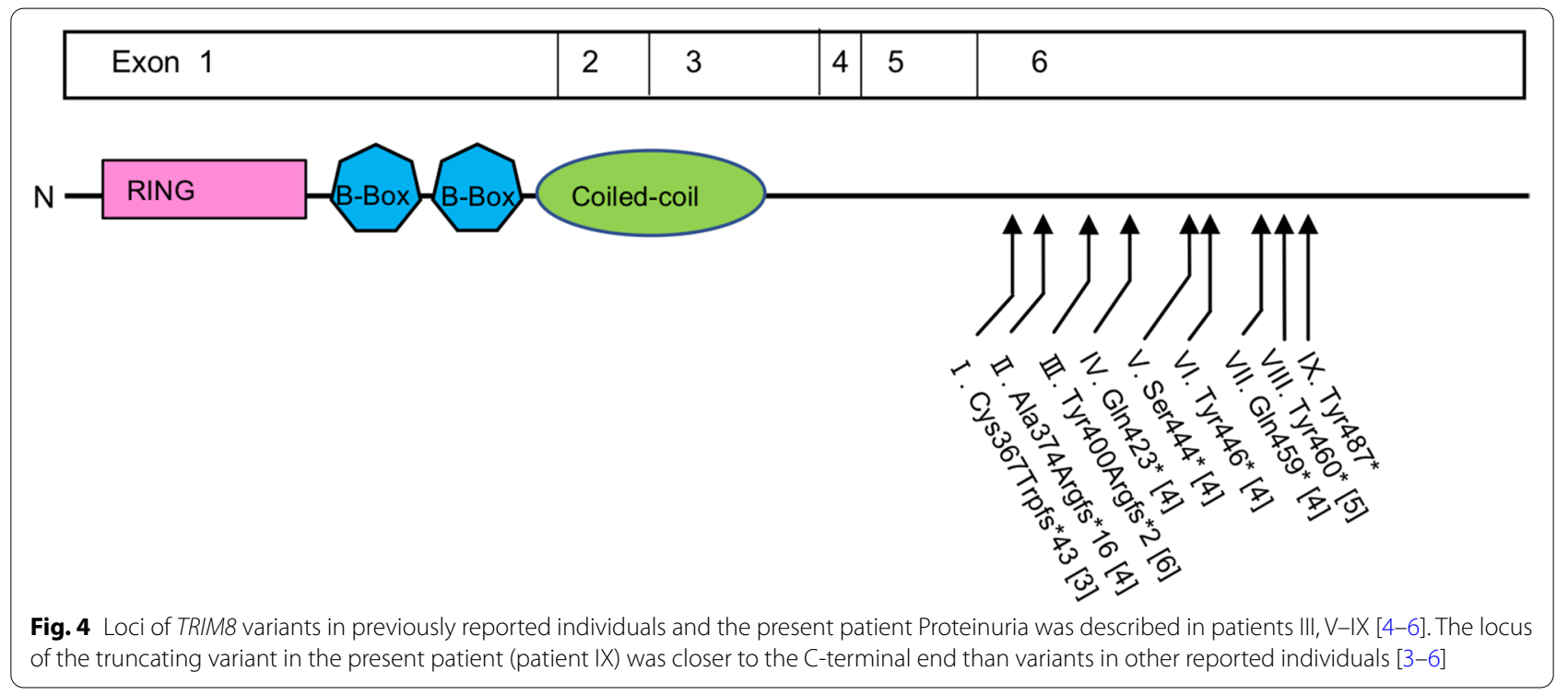

To date, at least eight reported individuals have been associated with heterozygous truncating variants in TRIM8, all of whom developed epilepsy or epileptic encephalopathy, including five individuals with proteinuria (Table 1 and Fig. 4) [3-6]. The present patient did not present with any neurological manifestations such as developmental delay and epilepsy. Brain MRI showed no abnormalities in the present patient, while cortical and subcortical atrophy and cysts in white matter on MRI have been described in the literature [4]. Because whole-exome sequencing showed that alternative allele counts were approximately half of the total reads, it is unlikely that the individual was a mosaic. The locus of the truncating variant in the present patient (p.Tyr487*) was closest to the C-terminal end than variants in other reported individuals (Table 1 and Fig. 4, patient IX). Nevertheless, the variant of patient III, who had mild developmental delay and well-controlled epilepsy [6], was located more 5', in the last exon than 5 patients with epileptic encephalopathy reported by Assoum et al. and Warren et al. [4, 5]. Therefore, a difference in the size of the truncated protein may not explain the difference in the severity of the neurological phenotype [6]. However, proteinuria tended to be documented in those individuals featuring TRIM8 variants that affected regions closer to the C-terminal end of the TRIM8 protein (Table 1 and Fig. 4, patient III, V-IX). Three of five individuals with proteinuria developed ESRD during childhood [5, 6]. Very recently, Weng et al. reported 12 individuals with TRIM8 variants clustering within the last exon between residues 390 and 487 of the 551 amino acid protein. All of them presented with nephrotic syndrome and neurologic disease, ten of whom showed FSGS on kidney biopsies [17]. ESRD occurred in 10 individuals at the age of 1 to 19 [17]. One of them, who had the same heterozygous variant as our patient (p.Tyr487*), presented with childhood-onset FSGS and neurological manifestations such as mild developmental delay, Tourette's syndrome-like symptoms, and autism spectrum [17]. Collectively, these findings expanded the clinical phenotypic spectrum of TRIM8 variants.

Renal pathological assessment of the present patient showed FSGS (Fig. 1A) and cystic dilatation of the distal tubules (Fig. 1B, 3I and J), which may be associated with other manifestations observed in our patient, such as polyuria and hyposthenuria. Although no tubulointerstitial changes were described in the individual reported by Warren et al. [5], a lack of TRIM8 expression in the tubular cells was noticed in the report by Warren et al. [5] To examine the possible superimposition of nephronophthisis, we performed genetic testing and examined 83 nephronophthisis causative genes (Table S2). However, no pathogenic variants in the genes currently known to cause nephronophthisis were identified in the present patient. Further studies remain necessary to characterize tubulointerstitial changes in patients with TRIM8 variants.

The mechanism underlying proteinuria and the cystic dilatation of tubules observed in our patient remains largely unknown. In this study, TRIM8 expression 
was observed in the nuclei of podocytes and tubular cells of control specimens. TRIM8 has been shown to enhance the translocation of signal transducer and activator of transcription 3 (STAT3) into the nucleus, and TRIM8 modulates STAT3 transcriptional potential in the nucleus [18]. Our study showed increased SOCS1 protein expression levels in kidney specimens from our patient, which was consistent with the report by Warren et al. Strong SOCS1 expression can inhibit cytokine signaling by binding to downstream signaling molecules such as Janus tyrosine kinases (JAK) [19], and inhibition of JAK/STAT3 activity attenuates the progression of glomerular and tubulointerstitial injury [20]. However, the associations between the TRIM8, SOCS1 protein expression, and renal manifestations remain unknown. It has been also described that TRIM8 induces p53-dependent cell cycle arrest [21]. Podocytes are terminally differentiated cells and have a limited capacity to divide. Wang et al. reported that the cellular lesion of FSGS is characterized by podocyte proliferation superimposed on sclerotic or collapsed glomerular tufts [22]. Therefore, TRIM8 dysfunction in podocytes may be associated with aberrant regulation of cell cycle, which may lead to the progression of FSGS. Cell cycle dysregulation has been also demonstrated in renal tubular epithelial cells in autosomal dominant polycystic kidney disease (ADPKD) [23]. Knockdown of $P k d 1$, a responsible gene for ADPKD, has been shown to reduce the amount of p53 and lower the fraction of cells in G1/S, suggesting that unchecked cell cycle progression is involved in the pathogenesis of tubular cyst growth [24]. Collectively, aberrant regulation of cell cycle induced by TRIM8 abnormalities may cause FSGS and the cystic dilatation of renal tubules.

In conclusion, we reported a patient with FSGS who had a de novo heterozygous TRIM8 variant without any neurological manifestations. Our results expanded the clinical phenotypic spectrum of TRIM8 variants CD10, cluster of differentiation 10; CD34, cluster of differentiation 10; EMA, epithelial membrane antigen; ESRD, end-stage renal disease; JAK, Janus tyrosine kinases; NMD, nonsense-mediated mRNA decay; SOCS1, Suppressor of cytokine signaling 1; STAT3, signal transducer and activator of transcription 3; TRIM8, tripartite motif containing 8; UPCR, urine protein to creatinine ratio.

\section{Abbreviations}

CD10: Cluster of differentiation 10; CD34: Cluster of differentiation 10; EMA: Epithelial membrane antigen; ESRD: End-stage renal disease; JAK: Janus tyrosine kinases; NMD: Nonsense-mediated mRNA decay; SOCS1: Suppressor of cytokine signaling 1; STAT3: Signal transducer and activator of transcription 3; TRIM8: Tripartite motif containing 8; UPCR: Urine protein to creatinine ratio.

\section{Supplementary Information}

The online version contains supplementary material available at https://doi. org/10.1186/s12882-021-02626-1.

Additional file 1: Figure S1. Immunofluorescence staining of the disease controls. Immunofluorescence staining, using an anti-TRIM8 antibody (red) and 4',6-diamidino-2-phenylindole (DAPI) (blue), in kidney specimens from a case with primary FSGS (a-d), and a case with nephronophthisis (e-h). TRIM8 protein was expressed in the nuclei of glomerular cells and tubular epithelial cells. (Original magnification, $\times 400$. Scale bar $=50 \mu \mathrm{m}$ ). Figure S2. Immunohistochemical staining of SOCS1. Immunohistochemical staining, using an anti-SOCS1 antibody, in the present case and a normal control case. The present case showed stronger SOCS1 protein expression in the cytoplasm of glomerular and tubular epithelial cells (A) than the control case (B). (Original magnification, $\times 200$. Scale bar $=$ $50 \mu \mathrm{m})$. SOCS1, Suppressor of cytokine signaling 1. Table S1. The list of 65 genes which represent monogenic causes of human focal segmental glomerulosclerosis and/or steroid-resistant nephrotic syndrome. Table S2. The list of 83 genes which represent monogenic causes of human nephronophthisis

\section{Acknowledgements}

We express our thanks to Professor Toshiyuki Yamamoto, at the Institute of Medical Genetics, Tokyo Women's Medical University for helpful discussions. This work was supported by Medical Research Institute (MRI), Tokyo Women's Medical University. We thank Lisa Giles, PhD, from Edanz Group (https://enauthor-services.edanzgroup.com/) for editing a draft of this manuscript.

\section{Authors' contributions}

Y.S., K.M., N.K., T.H., S.K., Y.H. and M.H. designed the study; Y.S., N.K., A.E. and T.H. performed the experiments; Y.S. and K.M. drafted the manuscript; Y.S. generated the figures; K.I., S.K., Y.H. and M.H. critically revised the paper; all authors approved the final version of the manuscript.

\section{Funding}

This work was supported by MEXT/JSPS KAKENHI [Grant numbers JP18K07857 to M.H. and JP18K07830 to K.M.] from the Ministry of Education, Culture, Sports, Science and Technology of Japan. The funding body played no role in the design of the study, collection, analysis, and interpretation of the data, or in writing the manuscript.JP18K07857,JP18K07830

\section{Availability of data and materials}

The datasets are not publicly available but are available from the first author on reasonable request.

\section{Declarations}

\section{Ethics approval and consent to participate}

The study was approved by the Institutional Review Board at Tokyo Women's Medical University (approval number 376). The guardians of the patient provided written informed consent.

\section{Consent for publication}

Written informed consent was obtained from the guardians of the patient for publication of this Case Report and any accompanying images. The copy of the written consent is available for review by the Editor of this journal.

\section{Competing interests}

The authors declare that they have no competing interests.

\section{Author details}

${ }^{1}$ Department of Pediatric Nephrology, Tokyo Women's Medical University, Tokyo, Japan. ${ }^{2}$ Department of Pediatrics and Adolescent Medicine, Juntendo University Graduate School of Medicine, Tokyo, Japan. ${ }^{3}$ Department of Pediatrics, Yamagata University School of Medicine, Yamagata, Japan. ${ }^{4}$ Department of Pediatrics, Graduate School of Medicine, The University of Tokyo, Tokyo, Japan. 
Received: 25 September 2020 Accepted: 5 December 2021

Published online: 20 December 2021

\section{References}

1. De Vriese AS, Sethi S, Nath KA, Glassock RJ, Fervenza FC. Differentiating primary, genetic, and secondary FSGS in adults: a clinicopathologic approach. J Am Soc Nephrol. 2018;29:759-74.

2. Warejko JK, Tan W, Daga A, Schapiro D, Lawson JA, Shril S, Lovric S, Ashraf S, Rao J, Hermle T, Jobst-Schwan T, Widmeier E, Majmundar AJ, Schneider R, Gee HY, Schmidt JM, Vivante A, van der Ven AT, Ityel H, Chen J, Sadowski CE, Kohl S, Pabst WL, Nakayama M, Somers MJG, Rodig NM, Daouk G, Baum M, Stein DR, Ferguson MA, Traum AZ, Soliman NA, Kari JA, El Desoky S, Fathy H, Zenker M, Bakkaloglu SA, Müller D, Noyan A, Ozaltin F, Cadnapaphornchai MA, Hashmi S, Hopcian J, Kopp JB, Benador N, Bockenhauer D, Bogdanovic R, Stajic N, Chernin G, Ettenger R, Fehrenbach H, Kemper M, Munarriz RL, Podracka L, Büscher R, Serdaroglu E, Tasic V, Mane S, Lifton RP, Braun DA, Hildebrandt F. Whole exome sequencing of patients with steroid-resistant nephrotic syndrome. Clin J Am Soc Nephrol. 2018;13:53-62.

3. Sakai Y, Fukai R, Matsushita Y, Miyake N, Saitsu H, Akamine S, Torio M, Sasazuki M, Ishizaki Y, Sanefuji M, Torisu H, Shaw CA, Matsumoto N, Hara T. De novo truncating mutation of TRIM8 causes early-onset epileptic encephalopathy. Ann Hum Genet. 2016;80:235-40.

4. Assoum M, Lines MA, Elpeleg O, Darmency V, Whiting S, Edvardson S, Devinsky O, Heinzen E, Hernan RR, Antignac C, Deleuze JF, Portes VD, Bertholet-Thomas A, Belot A, Geller E, Lemesle M, Duffourd Y, ThauvinRobinet C, Thevenon J, Chung W, Lowenstein DH, Faivre L. Further delineation of the clinical spectrum of de novo TRIM8 truncating mutations. Am J Med Genet. 2018;176A:2470-8.

5. Warren M, Takeda M, Partikian A, Opas L, Fine R, Yano S. Association of a De Novo Nonsense Mutation of the TRIM8 Gene With Childhood-Onset Focal Segmental Glomerulosclerosis. Pediatr Nephrol. 2020;35:1129-32.

6. McClatchey MA, du Toit ZD, Vaughan R, Whatley SD, Martins S, Hegde S, Naude JTW, Thomas DH, Griffiths DF. Genomics England Research Consortium, Clarke AJ, Fry AE. Focal segmental glomerulosclerosis and mild intellectual disability in a patient with a novel de novo truncating TRIM8 mutation. Eur J Med Genet. 2020;63:103972. https://doi.org/10.1016/j. ejmg.2020.103972.

7. Hattori M, Horita S, Yoshioka T, Yamaguchi Y, Kawaguchi H, Ito K. Mesangial phenotypic changes associated with cellular lesions in primary focal segmental glomerulosclerosis. Am J Kidney Dis. 1997;30:632-8.

8. Hashimoto T, Harita Y, Takizawa K, Urae S, Ishizuka K, Miura K, Horita S, Ogino D, Tamiya G, Ishida H, Mitsui T, Hayasaka K, Hattori M. In Vivo Expression of NUP93 and Its Alteration by NUP93 Mutations Causing Focal Segmental Glomerulosclerosis. Kidney Int Rep. 2019;31:1312-22.

9. Richards S, Aziz N, Bale S, Bick D, Das S, Gastier-Foster J, Grody WW, Hegde $M$, Lyon E, Spector E. Standards and guidelines for the interpretation of sequence variants: a joint consensus recommendation of the American College of Medical Genetics and Genomics and the Association for Molecular Pathology. Genet Med. 2015;17:405-24.

10. Rump LV, Asamoah B, Gonzalez-Escalona N. Comparison of commercial RNA extraction kits for preparation of DNA-free total RNA from Salmonella cells. BMC Res Notes. 2010;3:211.

11. Dyle MC, Kolakada D, Cortazar MA, Jagannathan S. How to get away with nonsense: Mechanisms and consequences of escape from nonsensemediated RNA decay. WIREs RNA. 2020;1 1:e1560.
12. Hara M, Yanagihara T, Takada T, Itoh M, Matsuno M, Yamamoto T, Kihara I. Urinary excretion of podocytes reflects disease activity in children with glomerulonephritis. Am J Nephrol. 1998;18:35-41.

13. Fina L, Molgaard HV, Robertson D, Bradley NJ, Monaghan P, Delia D, Sutherland DR, Baker MA, Greaves MF. Expression of the CD34 gene in vascular endothelial cells. Blood. 1990;75:2417-26.

14. Truong LD, Shen SS. Immunohistochemical diagnosis of renal neoplasms. Arch Pathol Lab Med. 2011;135:92-109.

15. Fleming S, Lindop GBM, Gibson AAM. The distribution of epithelial membrane antigen in the kidney and its tumors. Histopathology. 1985;9:729-39.

16. Reymond A, Meroni G, Fantozzi A, Meria G, Cairo S, Luzi L, Riganelli D, Zanaria E, Messali S, Cainarca S, Guffanti A, Minucci S, Pelicci PG, Ballabio A. The tripartite motif family identifies cell compartments. EMBO J. 2001;20:2140-51

17. Weng PL, Majmundar AJ, Khan K, Lim TY, Shril S, Jin G, Musgrove J, Wang M, Ahram DF, Aggarwal VS, Bier LE, Heinzen EL, Onuchic-Whitford AC, Mann N, Buerger F, Schneider R, Deutsch K, Kitzler TM, Klämbt V, Kolb A, Mao Y, Moufawad E, Achkar C, Mitrotti A, Martino J, Beck BB, Altmüller J, Benz MR, Yano S, Mikati MA, Gunduz T, Cope H, Shashi V, Undiagnosed Diseases Network, Trachtman H, Bodria M, Caridi G, Pisani I, Fiaccadori E, Abu Maziad AS, Martinez-Agosto JA, Yadin O, Zuckerman J, Kim A, UCLA Clinical Genomics Center, John-Kroegel U, Tyndall AV, Parboosingh JS, Innes AM, Bierzynska A, Koziell AB, Muorah M, Saleem MA, Hoefele J, Riedhammer KM, Gharavi AG, Jobanputra V, Pierce-Hoffman E, Seaby EG, O'Donnell-Luria A, Rehm HL, Mane S, D'Agati VD, Pollak MR, Ghiggeri GM, Lifton RP, Goldstein DB, Davis EE, Hildebrandt F, Sanna-Cherchi S. De novo TRIM8 variants impair its protein localization to nuclear bodies and cause developmental delay, epilepsy, and focal segmental glomerulosclerosis. Am J Hum Genet. 2021;108:357-67.

18. Venuto S, Castellana S, Monti M, Appolloni I, Fusilli C, Fusco C, Pucci P, Malatesta P, Mazza T, Merla G, Micale L. TRIM8-driven transcriptomic profile of neural stem cells identified glioma related nodal genes and pathways. Biochim Biophys Acta Gen Subj. 2019;1863:491-501.

19. Toniato E, Chen XP, Losman J, Flati V, Donahue L, Rothman P. TRIM8/ GERP RING Finger Protein Interacts with SOCS-1. J Biol Chem. 2002;277:37315-22.

20. Pace J, Paladugu P, Das B, He JC, Mallipattu SK. Targeting STAT3 signaling in kidney disease. Am J Physiol Renal Physiol. 2019;316:1 151-61.

21. Marzano F, Guerrini L, Pesole G, Sbisà E, Tullo A. Emerging Roles of TRIM8 in Health and Disease. Cells. 2021;10:561. https://doi.org/10.3390/cells 10030561.

22. Wang S, Kim JH, Moon KC, Hong HK, Lee HS. Cell-cycle mechanisms involved in podocyte proliferation in cellular lesion of focal segmental glomerulosclerosis. Am J Kidney Dis. 2004;43:19-27.

23. Lee K, Gusella GL, He JC. Epithelial proliferation and cell cycle dysregulation in kidney injury and disease. Kidney Int. 2021;100:67-78.

24. Kim H, Bae Y, Jeong W, Ahn C, Kang S. Depletion of PKD1 by an antisense oligodeoxynucleotide induces premature G1/S-phase transition. Eur J Hum Genet. 2004;12:433-40.

\section{Publisher's Note}

Springer Nature remains neutral with regard to jurisdictional claims in published maps and institutional affiliations.

Ready to submit your research? Choose BMC and benefit from:

- fast, convenient online submission

- thorough peer review by experienced researchers in your field

- rapid publication on acceptance

- support for research data, including large and complex data types

- gold Open Access which fosters wider collaboration and increased citations

- maximum visibility for your research: over 100M website views per year

At BMC, research is always in progress.

Learn more biomedcentral.com/submissions 